\title{
Estratégias de Coping de Crianças Vítimas e Não Vítimas de Violência Doméstica
}

\author{
Carolina Lisboa ${ }^{123}$ \\ Silvia Helena Koller \\ Fernanda Freitas Ribas \\ Kelly Bitencourt \\ Letícia Oliveira \\ Lízia Pacheco Porciuncula \\ Renata Busnello De Marchi \\ Universidade Federal do Rio Grande do Sul
}

\begin{abstract}
Resumo
Este estudo teve como objetivo investigar as estratégias de coping adotadas por crianças vítimas e não vítimas de violência doméstica, quando inseridas no microssistema escolar. Participaram da pesquisa 87 crianças divididas em dois grupos: 49 vítimas e 38 não vítimas de violência doméstica, as quais responderam a uma entrevista estruturada nas suas escolas, que visava a identificar os problemas mais freqüentes experienciados com os professores e com os colegas e as estratégias de coping utilizadas. As crianças vítimas de violência doméstica apontaram como problema de maior freqüência as agressões verbais por parte da professora e a estratégia de coping de agredir fisicamente para lidar nos conflitos com seus pares. As crianças não vítimas citaram com maior freqüência a busca de apoio de outras pessoas como estratégia para lidar com seus problemas junto aos colegas. As meninas adotaram a inação, quando enfrentam problemas com seus professores e se incomodam mais com as agressões verbais destes. Os resultados são discutidos levando em conta o contexto ecológico e as relações hierárquicas e apontam subsídios para programas de intervenção, que promovam resiliência e adaptação sadia de criançasà escola.

Palavras-chave: Coping; microssistema escolar; agressividade; resiliência; risco; proteção.
\end{abstract}

Coping Strategies of Domestic Violence Victimized and Non Victimized Children

\begin{abstract}
The present study aimed to investigate coping strategies of domestic violence victimized and non-victimized children in school's microsystem. Eighty-seven children, divided in two groups participated in this study: 49 victimized and 38 nonvictimized children. They answered a structured interview to identify the most frequent conflicts faced with teachers and classmates and the coping strategies to deal with those issues. The victimized children reported higher frequency of verbal aggression from teachers, and physical aggressions as coping strategies to deal with peers. The non-victimized children seemed to look for others' support as coping strategies to deal with problems they have with their classmates. Girls did not seem to act when they faced problems with their teachers, and they felt more upset with teacher's verbal aggression. Results are discussed based on the ecological context and hierarchical relations, and give subsidies out to support intervention programs, to promote resilience and children's healthy adaptation to school.

Keywords: Coping; school system; aggression; resilience; risk; protection.
\end{abstract}

A divulgação de notícias sobre violência doméstica atinge proporções alarmantes atualmente. Pesquisas, conferências, fóruns de debates, colóquios e livros são apresentados em profusão sobre esta questão, mas as políticas públicas ainda necessitam de aperfeiçoamento e maior comprometimento social para enfrentar esta realidade. O conhecimento de casos de abuso e violência, especialmente contra crianças e

\footnotetext{
${ }^{1}$ Endereço para correspondência: CEP-RUA/UFRGS, Instituto de Psicologia, Rua Ramiro Barcelos 2600/104, 90035-003, Porto Alegre, RS. Fone: (51) 33165150, Fax: (51) 33304797. E-mail: cep_rua@ufrgs.br 2 Apoio $\mathrm{CNPq}$

${ }^{3}$ Este estudo faz parte da Dissertação de Mestrado em Psicologia do Desenvolvimento (UFRGS) da primeira autora, orientada pela segunda autora.
}

mulheres, pode ser reflexo dos avanços na comunicação e da globalização, mas pode sugerir que as intervenções e programas de prevenção existentes não estejam alcançando total nível de eficácia necessária para superar este problema. A capacitação de profissionais que lidam com crianças e outras vítimas potenciais de violência deve ser uma prioridade social, visando a muni-los de ferramentas e conhecimentos para identificar e encaminhar quaisquer casos que sejam suspeitos ou evidentes de violência.

Pesquisadores preocupados em compreender a magnitude e a complexidade das situações de risco na infância têm voltado sua atenção para a maneira pela qual crianças lidam com situações estressantes (como a violência doméstica, por exemplo) durante seu processo de 
desenvolvimento. Muitos estudos têm sido orientados pelo referencial da saúde, visando a investigar comportamentos ou ações adotadas para lidar com problemas (Cowan, Cowan \& Schulz, 1996; Heller, Larrieu, D'Imperio \& Boris, 1999; Jessor, 1993). Um dos aspectos fundamentais destes estudos consiste em identificar aspectos sadios preservados que se ativam diante de situações estressantes e geram resultados adequados para que vítimas sigam o curso de seu desenvolvimento, tais como características de personalidade, uso de estratégias de coping e apoio social e afetivo (Lazarus \& Folkman, 1984; Ryan-Wenger, 1992).

O conceito de coping vem sendo estudado por estar associado ao ajustamento social e saúde. As estratégias de coping consistem em mudanças cognitivas e esforços comportamentais conscientes, que gerenciam demandas internas e externas, percebidas pela criança como estressantes e avaliadas como sobrecarga aos recursos pessoais (Lazarus \& Folkman, 1984; Zeidner \& Endler, 1996). O termo coping não tem sido traduzido para o Português, pois não existem palavras equivalentes para definir este conceito (Ex.: "lidamento" ou "lidação"). A tradução por "enfrentamento", utilizada tentativamente, provoca confusão, pois esta palavra implica uma ação direcionada a algum alvo, enquanto que a inação pode ser apontada como uma estratégia de coping comum em crianças. Estratégias de coping são ações deliberadas, conscientes, que podem ser aprendidas, usadas e descartadas e cujo objetivo é lidar com o estresse percebido (Ryan-Wenger, 1992). Constituem-se em um processo flexível e intencional e orientado para o futuro, na busca do alívio do stress (Parker \& Endler, 1996).

O processo de coping envolve quatro conceitos principais: (a) interação da pessoa com o ambiente; (b) administra a situação estressora; (c) pressupõe a noção de avaliação e percepção da pessoa focalizada; e, (d) mobilização de esforços cognitivos e comportamentais para administrar, reduzir, minimizar ou tolerar as demandas internas e/ou externas, que emergem na interação pessoa-ambiente (Folkman \& Lazarus, 1980). Baseado nestes aspectos deve ser analisado sob uma perspectiva ecológica, inserido no contexto do problema, avaliando os recursos da pessoa, e os processos utilizados para interpretar o problema (Bronfenbrenner, 1979/1996, 1989, 1993, 1995; Bronfenbrenner \& Morris, 1998).

Ao perceber a situação estressante (problema), a pessoa experimenta uma sensação emocional desagradável, buscando adotar estratégias que minimizem seu sofrimento. As estratégias de coping podem ser diferenciadas, sob uma perspectiva cognitiva, em duas categorias: coping focalizado no problema e coping focalizado na emoção (Folkman \& Lazarus, 1980). Coping focalizado no problema é um esforço para agir contra o stress em si a fim de modificá-lo. A estratégia que emerge altera o problema existente na relação pessoaambiente, como, por exemplo, estudar mais para um segundo teste escolar, quando o desempenho não foi tão satisfatório no primeiro. Coping focalizado na emoção é definido como um esforço para regular e aliviar o estado afetivo associado ao stress ou resultante do evento estressante. São exemplos de coping focalizado na emoção: sair para correr diante de uma situação que gere medo. Tais esforços visam a reduzir a sensação física desagradável provocada pelo stress, a fim de modificar o estado emocional. No caso de crianças, observa-se o uso de estratégias de coping, geralmente, focalizadas na emoção, pois elas, na maioria das vezes, dispõem de recursos mais precários ou menos sofisticados para lidar com estressores. Tais situações para criança estão comumente, fora do controle direto, dependendo de seus pais e cuidadores, família e/ou professores (Almquist \& Hwang, 1999; Ryan-Wenger, 1992). A violência doméstica é um estressor cuja resolução está fora do seu controle, por serem gerados por relações hierarquicamente determinadas, nas quais o agressor detem o poder e a força física sobre a criança.

Considerando que o processo de coping consiste em uma interação entre a pessoa e seu ambiente, é importante salientar que as estratégias variam de acordo com os contextos no qual a pessoa interage, bem como de acordo com suas características pessoais. Fatores situacionais influenciam as respostas de coping e determinam mudanças nos tipos de estratégias utilizadas. O contexto é fundamental na escolha das alternativas e recursos para lidar com os problemas. Determinadas ações são adequadas para certos contextos e determinadas situações, mas não seriam escolhidas pelas crianças em outras circunstâncias (Amirkhan, 1990; Boekaerts, 1996; Stone, Greenberg, Kennedy-Moore \& Newman, 1991). Estratégias de coping são antecipadas por mecanismos de avaliação pessoal e ambiental. A pessoa ativa processos cognitivos para identificar a situação crítica com a qual se depara, checar suas condições atuais, experiências eficazes e ineficazes anteriores, nível e grau de risco envolvido nesta e analisar os recursos disponíveis e as alternativas possíveis para lidar com o problema (Folkman \& Lazarus, 1980). O processo de coping pode variar quando o problema é percebido em casa ou na escola, por exemplo. Nestes ambientes, as diferenças se relacionam, basicamente, aos diferentes tipos de relações interpessoais nas quais coexistem questões de hierarquia e poder. Crianças lidam de forma distinta ao enfrentar problemas com seu grupo de iguais, do que com seus pais e professores (Antoniazzi, 2000; Dell'Aglio, 2000; Lisboa, 2001). Diferenças significativas podem ser observadas nas ações e estratégias utilizadas, 
principalmente aquelas relativas a aproximação e evitação, nos domínios escolar e familiar (Antoniazzi, 2000). Estratégias agressivas e de busca de apoio social ocorrem com freqüência em conflitos com pares, enquanto que com adultos, são comuns estratégias de ação direta quando a negociação é possível, e de evitação ou inação, quando a negociação não é possível, devido a questões de hierarquia e autoridade (Dell'Aglio, 2000; Lisboa, 2001).

O contexto ecológico escolar ilustra claramente um sistema no qual as relações de hierarquia estão presentes e podem eliciar situações estressoras. A influência da escola é significativa no desenvolvimento infantil, pois as crianças passam a maior parte do tempo na escola. Além de ter um papel fundamental na aprendizagem infantil, as interações na escola promovem a regulação da atenção, da emoção e do comportamento (Eccles \& Roeser, 1999). A escola pode auxiliar, ainda, no aumento da auto-estima e da auto-eficácia, por meio de oportunidades que requeiram habilidades sociais, do relacionamento com o grupo de iguais, e de situações que discutam valores, normas e regras. As relações de hierarquia presentes no contexto da escola devem ser identificadas e avaliadas segundo seu potencial de risco ou proteção para o desenvolvimento infantil (Rutter, 1987; Zimmermann \& Arunkumar, 1994).

Diferenças entre os sexos podem também influenciar os processos de coping (Seiffge-Krenke, 1990). De uma maneira geral, meninos e meninas apresentam poucas diferenças em nível cognitivo, comportamental e emocional na infância, ficando estas mais bem demarcadas com a chegada da adolescência. Entretanto as diferenças entre os sexos na expressão da agressividade aparecem desde a infância. Os meninos, de acordo com a literatura, são mais agressivos que as meninas, envolvendo-se com maior freqüência em conflitos que utilizam força física. Embora consideradas menos agressivas, as meninas tendem a manifestar indiretamente a agressão, expressando verbalmente sua hostilidade. Seiffge-Krenke (1990) observou que meninas adolescentes tendem a utilizar mais freqüentemente estratégias de busca de apoio social e ações diretas, já os meninos tendem a empregar estratégias de evitação diante de situações estressantes. Diferenças entre os sexos devem, no entanto, ser analisadas sob uma perspectiva ecológica, a partir do entendimento da interação entre fatores bio-psicológicos (dimensão Pessoa) e fatores ambientais (dimensão Contexto). A aparência de meninos e meninas e sua capacidade física relacionada à força e habilidade para realizar determinadas atividades são características biológicas que provocam ou inibem respostas do ambiente e das pessoas com quem têm contato (Bronfenbrenner \& Morris, 1998). Cada sexo é tratado de forma distinta em resposta às expectativas geradas sobre seus comportamentos. Estes eventos resultam em um processo de socialização distinto. Os meninos devem ser fortes, de temperamento difícil, com adequada coordenação motora e as meninas fracas, delicadas, obedientes e mais sensíveis (Coie \& Dodge, 1998; Ruble \& Martin, 1998). Meninas são educadas para desenvolverem respostas comportamentais mais prósociais, já os meninos para serem independentes e adotarem estratégias competitivas (Lopez \& Little, 1996). Socialização ocorre também por aprendizagem vicária, respondendo a influências sócio-histórico-culturais (Bandura, 1969, 1997; Ruble \& Martin, 1998). Crianças aprendem padrões culturais e comportamentos típicos ao seu sexo biológico, por meio de observação dos modelos masculinos e femininos relevantes com os quais convivem (professores e pais, principalmente).

O contexto influencia significativamente na forma com que as crianças lidam com as situações estressoras. A violência doméstica é um aspecto do microssistema familiar que influencia nos processos cognitivos e emocionais das crianças, podendo gerar ineficácia na utilização de estratégias de coping. Crianças que presenciam situações de violência no ambiente doméstico, seja como testemunhas ou vítimas diretas, tendem a desenvolver um repertório de estratégias pequeno e qualitativamente diferente das demais crianças (Caminha, 1999; Lisboa, 2001). O ambiente agressivo gera a aprendizagem de comportamentos também agressivos, como forma de resolução de problemas. $\mathrm{Na}$ escola, por serem mais agressivas, crianças vítimas de violência doméstica podem ser rejeitadas pelos colegas e professores, gerando maior stress e afetando o processo de aprendizagem e de estabelecimento de relações de companheirismo (Ladd \& Burgees, 1999). A utilização de força para influenciar ou controlar pessoas e eventos (coerção) ou para resistir a imposições externas (resistência) pode ser eficaz para redução da sensação desagradável provocada pela percepção de um stress e atingir o objetivo imediato a que se propõe. Uma criança pode, por exemplo, bater no colega que sentou em seu lugar para retirá-lo, mas sua atitude acarretará conseqüências negativas para o relacionamento social no ambiente escolar. As crianças visam, através do uso da força como observam no ambiente doméstico, a suplantar ou a subverter os objetivos dos outros e a impor sua própria vontade, provocando reações adversas, conflitos e rejeição em sua direção, além de estados emocionais negativos nos demais (Bandura \& Walters, 1959; Carver \& Scheier, 1994; Rubin, Coplan, Nelson, Cheah \& Lagace-Seguin, 1999; Summerfeldt \& Endler, 1996).

A criança vítima de violência doméstica aprende estratégias agressivas como sendo a maneira adequada de lidar com possíveis contrariedades e forma, assim, 
repertório destas respostas na sua memória (Bandura \& Walters, 1959; Coie \& Dodge, 1998). Quando se depara com uma situação de stress, utiliza estratégias de coping agressivas, respondendo a um ambiente que falhou em the oferecer outras alternativas para resolução de seus problemas (Coie \& Dodge, 1998; Jessor, 1993; Loeber \& Hay, 1997; Pierre \& Layzer, 1998). Podem, também, adotar estratégias de coping do tipo internalizadas (culpar-se) ou externalizadas (culpar outra pessoa, gritar ou bater). São, em geral crianças ansiosas, com dificuldades de concentração, hipervigilantes e com elevados níveis sentimentos de culpa. Utilizam-se, muitas vezes, associadas à agressividade, estratégias de coping evitativas, revelando desejo que o problema nunca tenha ocorrido para tentar alcançar aceitação social (Almquist \& Hwang, 1999; Cummings, Hollenbeck, Ianotti, RadkeYarrow \& Zahn-Waxler, 1986).

O presente estudo investiga as estratégias de coping de meninos e meninas, vítimas e não vítimas de violência doméstica, com o objetivo de identificar os problemas apontados por crianças, no microssistema escolar, com relação às questões de hierarquia envolvidas (relações com professores e colegas). Visa, ainda, a identificar as estratégias de coping utilizadas por crianças de ambos os grupos, buscando diferenças entre os grupos de vítimas e de nãovítimas e por sexo. São sublinhadas as características de risco e proteção envolvidas, para subsidiar para intervenções e programas de prevenção em escolas, junto às crianças e aos professores.

\section{Método}

\section{Participantes}

Participaram deste estudo 87 crianças, com idades entre 7 e 12 anos $(m=9,06 ; d p=1,36 ; \mathrm{G} 1=44 ; \mathrm{G} 2=43)$, divididos em dois grupos. O Grupo 1 foi composto por 49 crianças vítimas de violência doméstica que apresentaram ocorrência de, pelo menos, uma queixa de violência doméstica contra as mesmas (meninos $=25$; meninas $=24$ ). O Grupo 2 foi composto por 38 crianças não vítimas de violência doméstica, ou seja, para as quais inexistia qualquer queixas ou relato de violência $($ meninos $=19$; meninas $=19)$. Todas crianças estavam regularmente matriculadas em escolas da rede municipal e/ou estadual de Porto Alegre e Grande Porto Alegre, no Ensino Fundamental, e pertenciam a camadas de nível sócio-econômico baixo (definido pelo local de residência, tipo de escola, profissão e nível de escolaridade dos pais).

\section{Instrumentos}

\section{Entrevista estruturada}

A entrevista colheu dados sócio-demográficos das crianças, os tipos de problemas comumente enfrentados na escola com professores e com colegas e as estratégias de coping utilizadas pelas mesmas para lidar com estes. Também foram investigados os sentimentos das crianças no momento da percepção do problema e depois da ocorrência e/ou resolução deste e a auto-avaliação sobre as estratégias adotadas. Algumas perguntas iniciais da entrevista tinham o objetivo de criar vínculos com a criança e não foram consideradas na categorização (Anexo A).

\section{Procedimentos}

Em um primeiro momento, foi feito um contato com escolas para a realização do estudo. Os procedimentos e objetivos da pesquisa foram explicados em reuniões, junto à direção da instituição, equipe de orientação educacional e professores, solicitando-se o consentimento destes e uma autorização por escrito em nome das escolas para sua execução. Foram levantados os nomes das crianças para formação dos dois grupos. O Grupo 1 foi composto por crianças com queixas de violência doméstica registradas na escola, com encaminhamento ao Conselho Tutelar e ao Departamento Médico Legal. Também foram incluídas no Grupo 1, crianças supostamente vítimas de violência por apresentarem indicadores (físicos, psicológicos e/ou comportamentais) identificados pelas professoras e orientadoras educacionais das escolas. Algumas destas suspeitas foram confirmadas durante a entrevista, sendo as crianças encaminhadas ao Conselho Tutelar. O Grupo 2 foi composto por crianças sem queixa ou suspeita de violência doméstica.

Para a realização das entrevistas foi solicitado o consentimento informado dos pais das crianças. No entanto, este procedimento gerou muitas dificuldades e dilemas para os pesquisadores. O objetivo de solicitar este consentimento embasa uma questão ética importante que visa, principalmente, à proteção do participante da pesquisa. Surgiram questionamentos baseados no fato de que pais com história de abuso físico ou sexual, sem condenação e sem perda de pátrio poder, embora legalmente responsáveis, não seriam moralmente aptos para consentir ou não com a participação na pesquisa, do ponto de vista da equipe. No entanto, estes mesmos pais provavelmente não consentiriam com a inclusão de seus filhos na pesquisa, por temor à futura exposição do caso, ou ainda, poderiam coagir a criança a mentir, causando maior risco ainda. $\mathrm{O}$ não consentimento destes pais provocaria a impossibilidade de execução da pesquisa ou, pelo menos, um viés importante na amostra. Outro aspecto crítico referia-se à validade de consentimentos assinados por pais que seriam identificados durante as entrevistas como violentos ou abusadores e que seriam, certamente, denunciados pela equipe. As dificuldades quanto ao consentimento informado iniciaram-se quando os pais 
foram chamados à escola. Muitos não compareceram, outros eram analfabetos e não podiam assinar o documento ou com baixa escolaridade e com dificuldade de avaliar riscos e benefícios da pesquisa, ou de demonstrar interesse pelo processo e estar realmente cientes do sentido real de sua autorização. Diante destas dificuldades, a equipe optou por consultar o Comitê de Ética da Universidade Federal do Rio Grande do Sul, o Ministério Público do Estado do Rio Grande do Sul e outros profissionais da área jurídica na busca de uma solução para estes problemas. Foram consultados o Código de Ética Profissional da Psicologia e a Resolução N. 196/96 do Ministério da Saúde (1996), que era o único código existente naquela ocasião. Foram, também, revisados códigos de ética internacionais (Society for Research in Child Development, www.srcd.org), discutindo-se a validade do consentimento de pais abusadores e que podem vir a ser denunciados, perdendo o pátrio poder sobre os filhos e a importância de eliminar entraves que dificultem a pesquisa junto a famílias com história de violência doméstica. De qualquer forma, foi exigido pela Universidade que o termo de consentimento informado fosse assinado pelos pais e/ou responsáveis. Foi obtido também, por opção da equipe, o termo de consentimento informado das Escolas. A discussão sobre as questões éticas envolvidas nesta pesquisa gerou produção científica sobre os dilemas enfrentados por pesquisadores sobre famílias com história de violência doméstica (Lisboa \& Koller, 2000) e consultas e discussões e, de uma certa forma, subsidiaram alguns itens da Resolução 016 do Conselho Federal de Psicologia (2000) que na época ainda não havia sido homologada.

Apesar das inúmeras dificuldades, o consentimento informado foi solicitado e obtido, embora, na maioria das vezes, isto tenha sido percebido pela equipe apenas como um procedimento burocrático. A exigência de um consentimento informado não é discutida para pesquisas em geral, mas diante das implicações mencionadas anteriormente pode representar obstáculo ou inviabilidade para pesquisas junto a famílias com história de violência doméstica, evitando não só o avanço científico, mas possibilidades de discussões em torno de um problema de saúde pública do Brasil e que diz respeito a todos os cidadãos. Após a solicitação do consentimento da escola e dos pais, entrou-se em contato com as crianças, explicando-lhes os procedimentos da pesquisa e solicitando sua participação. Neste momento, também foi solicitada a autorização das crianças para a gravação das entrevistas. As entrevistas foram realizadas, individualmente, em salas cedidas pelas escolas. Foram gravadas e transcritas literalmente.

\section{Resultados}

Os resultados obtidos na Entrevista Semi-Estruturada foram submetidos a uma análise do conteúdo das respostas, criadas categorias de sentido e calculadas freqüências e percentagens. A Tabela 1 apresenta as freqüências e percentagens das respostas das crianças com relação aos problemas que enfrentam com suas professoras no microssistema escolar.

Ao serem questionadas sobre um problema ocorrido com suas professoras no contexto escolar, a maior parte das crianças se refere à categoria "Repreensões a certos comportamentos" (38,2\%), que inclui castigos, ocorrências, bilhetes para os pais, advertências e repreensões orais em sala de aula por parte da professora, em resposta a algum comportamento das crianças, julgado inadequado ou errado

Tabela 1

Freqüências e Percentagens das Respostas à Pergunta: "Conte-me um problema com a sua professora" (N=89; respostas múltiplas)

\begin{tabular}{lcc}
\hline Categorias & Freqüência & $\%$ \\
\hline Repreensões & 34 & 38,2 \\
Agressões verbais & 25 & 28 \\
Prescrição de tarefas difíceis & 7 & 7,8 \\
Não atender a seus pedidos & 7 & 7,8 \\
Doença ou ausência da professora & 5 & 5,6 \\
Agressão verbal dos alunos contra a professora & 3 & 3,3 \\
Não tem problema & 3 & 3,3 \\
Outros & 3 & 3,3 \\
Agressões físicas & 1 & 1,1 \\
Incapacidade para controlar a bagunça & 1 & 1,1 \\
\hline Total & 89 & 100 \\
\hline
\end{tabular}


pela mesma. A segunda maior freqüência de respostas referese à categoria "Agressões Verbais" (28\%), incluindo xingamentos, gritos e ironias da professora para com as crianças, independente de estas apresentarem comportamentos inadequados.

A Tabela 2 mostra o relato das crianças com relação aos seus sentimentos ao perceberem o problema. Cinqüenta e seis por cento das crianças refere se sentir mal, chateado(a) ou triste, quando percebe um problema com a professora. Outras crianças relataram não sentir nada (19\%) e 13\% informaram sentir raiva, nervosismo, braveza.

A Tabela 3 mostra que a estratégia de coping que as crianças relataram utilizar com maior freqüência para lidar com problemas com a sua professora é "Não fazer nada" (65,5\%).
$\mathrm{Na}$ Tabela 4 estão descritas as respostas das crianças quando questionadas sobre sua auto-avaliação das estratégias de coping relatadas.

A Tabela 4 mostra os resultados da questão: "Se este problema acontecesse de novo o que você faria?", que investiga a avaliação das crianças sobre as estratégias de coping que relataram adotar para lidar com um problema com suas professoras. A maioria das crianças mencionou que faria a mesma coisa que já havia relatado, justificando que: não existem outras alternativas de estratégias, uma vez que a professora tem sempre a razão $(51,6 \%)$; que a estratégia relatada resolve o problema e por isto a utilizariam de novo $(36,6 \%)$ e também que o uso da mesma estratégia evita com que elas sejam mais repreendidas na escola $(11,6 \%)$.

Tabela 2

Frequiencias e Percentagens das Respostas à Pergunta: "O que você sentiu na bora do problema com a professora?" $(n=84)$

\begin{tabular}{lcc}
\hline Categorias & Freqüência & $\%$ \\
\hline Mal, chateado, triste & 47 & 56 \\
Nada & 16 & 19 \\
Raiva, nervosismo, braveza & 11 & 13 \\
Outros & 8 & 9,5 \\
Não sabe & 1 & 1,2 \\
Bem & 1 & 1,2 \\
\hline Total & 84 & 100 \\
\hline
\end{tabular}

Tabela 3

Freqüências e Percentagens das Estratégias de Coping que as Crianças Relatam Adotar para Lidar com Problemas com a Professora ( $n=88$; respostas múltiplas)

\begin{tabular}{lcc}
\hline Categorias & Freqüência & $\%$ \\
\hline Não fazer nada & 57 & 65,5 \\
Conversar com a professora & 6 & 6,9 \\
Estudar mais & 6 & 6,9 \\
Sair da sala ou lugar onde ocorreu o problema & 6 & 6,9 \\
Obedecer à professora & 4 & 4,6 \\
Outros & 4 & 4,6 \\
Buscar apoio com outras pessoas & 3 & 3,4 \\
Enfrentar a professora & 2 & 2,3 \\
\hline Total & 88 & 100 \\
\hline
\end{tabular}

Tabela 4

Freqüências e Percentagens das Categorias Identificadas a partir das Justificativas sobre a Auto-Avaliação das Crianças das suas Estratégias de Coping Relacionadas aos Problemas com a Professora

\begin{tabular}{|c|c|c|c|c|c|}
\hline \multicolumn{3}{|c|}{ Usaria a mesma estratégia $(n=60)^{*}$} & \multicolumn{3}{|c|}{ Usaria uma estratégia diferente $(n=22)^{*}$} \\
\hline Categorias & Freqüência & $\%$ & Categoria & Freqüência & $\%$ \\
\hline $\begin{array}{l}\text { A professora tem sempre a } \\
\text { razão }\end{array}$ & 31 & 51,6 & Porque não adianta & 12 & 54,5 \\
\hline Porque resolve & 22 & 36,6 & Existem outras & 10 & 45,5 \\
\hline $\begin{array}{l}\text { Para evitar maiores } \\
\text { repreensões na escola }\end{array}$ & 7 & 11,6 & $\begin{array}{l}\text { estratégias possíveis } \\
\text { de serem utilizadas }\end{array}$ & & \\
\hline Total & 60 & 100 & & 22 & 00 \\
\hline
\end{tabular}


Tabela 5

Freqüencias e Percentagens das Respostas à Pergunta: "O que você sentiu depois que terminou ou se resolven o problema com a sua professora?" $(n=60)$

\begin{tabular}{lcc}
\hline Categorias & Freqüência & $\%$ \\
\hline Bem, aliviado, melhor, legal & 33 & 55 \\
Raiva, braveza, mal-estar, tristeza, chateação & 14 & 23,5 \\
Outros & 7 & 11,7 \\
Nada & 6 & 1 \\
\hline Total & 60 & 100 \\
\hline
\end{tabular}

Quando afirmaram que não usariam a mesma estratégia, as justificativas se dividiram em: porque a estratégia não resolve, ou seja, não é eficaz (54,5\%); e, porque existem outras possibilidades de estratégias diferentes das mencionadas e que, segundo as crianças, poderiam resolver o seu problema (45,5\%). Na Tabela 5 estão descritos os sentimentos que as crianças relataram ao perceber o problema. A maioria das crianças relatou sentir-se bem após o problema ter se resolvido ou terminado $(55 \%)$. Outras crianças referiram sentir raiva, braveza, etc. $(23,5 \%)$.

A Tabela 6 descreve as respostas sobre os problemas que as crianças relataram envolvendo seus colegas (grupo de iguais).
Os problemas com colegas mais relatados pelas crianças foram as agressões físicas por parte dos mesmos (35,3\%). Também foram citadas com freqüência as categorias: "Ver os colegas brigando entre si" (23,2\%) e "Agressões verbais" $(19,1 \%)$.

De acordo com a Tabela 7, a maioria das crianças sentese mal quando percebe o problema com os colegas (38,3\%). Algumas crianças informaram sentir raiva e outros sentimentos associados $(34,2 \%)$.

De acordo com a Tabela 8 , a estratégia de coping mais utilizada pelas crianças, quando enfrentam problemas com seus colegas, é a busca do apoio de alguém como professora, pais, irmãos mais velhos, primos, direção da

Tabela 6

Freqüiencias e Percentagens das Respostas à Questão: "Conte-me um problema com algum colega seu" (respostas múltiplas)

\begin{tabular}{lcc}
\hline Categorias & Freqüências & $\%$ \\
\hline Agressões físicas & 35 & 35,3 \\
Ver colegas brigando entre si & 23 & 23,2 \\
Agressões verbais & 19 & 19,1 \\
Outros & 8 & 8 \\
Ameaças & 6 & 6 \\
Estrago ou roubo de materiais pessoais & 5 & 5 \\
Mentiras sobre seu comportamento & 2 & 2 \\
Separação dos meus amigos & 1 & 1 \\
Total & 97 & 100 \\
\hline
\end{tabular}

Tabela 7

Freqüências e Percentagens das Respostas à Pergunta: "O que você sentiu na hora do problema com seu colega?" $(n=73)$

\begin{tabular}{lcc}
\hline Categorias & Freqüência & $\%$ \\
\hline Mal & 28 & 38,3 \\
Raiva, braveza, nervosismo & 25 & 34,2 \\
Não sente nada & 10 & 13,6 \\
Dor & 10 & 13,6 \\
\hline Total & 73 & 100 \\
\hline
\end{tabular}


Tabela 8

Freqüências e Percentagens das Estratégias de Coping que as Crianças Informam Utilizar para Lidar com Problemas com o Colega (respostas múltiplas)

\begin{tabular}{lcc}
\hline Categorias & Freqüência & $\%$ \\
\hline Buscar apoio de alguém & 29 & 29,8 \\
Agressões físicas & 19 & 19,5 \\
Não fazer nada & 18 & 18,5 \\
Romper a amizade com o colega & 8 & 8,2 \\
Agressões verbais & 7 & 7,2 \\
Separar brigas dos colegas & 6 & 6,2 \\
Sair do local onde ocorreu o problema & 6 & 6,2 \\
Conversar com o colega & 2 & 2,2 \\
Chorar & 1 & 1,2 \\
Estudar mais & 1 & 1,2 \\
\hline Total & 89 & 100 \\
\hline
\end{tabular}

escola, etc. (29,8\%). Também foram citadas com freqüência alta as categorias: "Agressões Físicas" (19,5\%) e "Não fazer nada" (18,5\%).

Os dados apresentados na Tabela 9 revelam que a maioria das crianças usaria a mesma estratégia, porque adianta, ou seja, porque a avaliam como eficaz $(64,2 \%)$. Entretanto, grande parte das crianças levantou novas possibilidades de estratégias (49\%). As crianças que usariam estratégias diferentes também relatam que adotariam uma nova estratégia, porque a estratégia que relataram ter usado, anteriormente, não resolveu seu problema, não foi eficaz $(45 \%)$.

Segundo a Tabela 10, a maioria das crianças informou sentir-se bem, melhor, otimista e calmo(a) depois que terminou o problema $(50 \%)$.

Tabela 9

Frequiencias e Percentagens das Categorias Referentes às Justificativas da Auto-Avaliação das Crianças sobre suas Estratégias de Coping Relacionadas aos Problemas com os Colegas (respostas múltiplas)

Usaria a mesma estratégia $(n=42)^{*} \quad$ Usaria uma estratégia diferente $(n=51)^{*}$

\begin{tabular}{|c|c|c|c|c|c|}
\hline Categorias & Freqüência & $\%$ & Categorias & Freqüência & $\%$ \\
\hline Porque resolve & 27 & 64,2 & Porque existem outras & 25 & 49 \\
\hline $\begin{array}{l}\text { Porque é a única coisa que } \\
\text { posso fazer }\end{array}$ & 8 & 19 & $\begin{array}{l}\text { estratégias possíveis de } \\
\text { serem utilizadas }\end{array}$ & & \\
\hline Porque é certo & 6 & 14,2 & Porque não resolve & 23 & 45 \\
\hline $\begin{array}{l}\text { Porque não quero me } \\
\text { prejudicar mais na escola }\end{array}$ & 1 & 2,3 & $\begin{array}{l}\text { Faria outra coisa } \\
\text { seguindo orientação de } \\
\text { outros }\end{array}$ & 3 & 5,8 \\
\hline Total & 42 & 100 & & 51 & 100 \\
\hline
\end{tabular}

Tabela 10

Freqüências e Percentagens das Respostas à Pergunta: "O que você sentiu depois que terminou ou se resolven o problema com seu colega?" $(n=72)$

\begin{tabular}{lcc}
\hline Categorias & Freqüência & $\%$ \\
\hline Bem melhor, otimista, calmo & 36 & 50 \\
Mal, ruim, pior & 15 & 20,8 \\
Nada & 10 & 13,8 \\
Arrependido & 5 & 6,9 \\
Bravo & 2 & 2,7 \\
Vergonha & 2 & 2,7 \\
Assustado & 1 & 1,3 \\
Vontade de falar com a mãe & 1 & 1,3 \\
\hline Total & 72 & 100 \\
\hline
\end{tabular}




\section{Cruzamentos entre os Grupos 1 e 2 e as Categorias Identificadas}

Foi utilizado o Teste de Qui-quadrado $\left(X^{2}\right)$ para verificar as diferenças entre os Grupos 1 (crianças vítimas de violência doméstica) e 2 (crianças não vítimas de violência doméstica) com relação às categorias identificadas na entrevista referentes aos tipos de problemas com professores e colegas enfrentados e relatados e às estratégias de coping adotadas. A seguir serão descritas apenas as análises que obtiveram resultados significativos.

De acordo com a Tabela 11, existe diferença significativa entre os Grupos 1 e 2 no que se refere à categoria "Agressões Verbais", levantada a partir da questão "Conte-me um problema com a sua professora". As crianças vítimas de violência doméstica (Grupo 1) referem com maior freqüência este tipo de problema com a professora do que as crianças não vítimas (Grupo 2).

Como mostra a Tabela 12, existe diferença significativa ente os Grupos 1 e 2 com relação ao uso de agressões físicas como estratégia de coping quando o problema é com o colega. Verifica-se que as crianças vítimas de violência doméstica (Grupo 1) utilizam mais esta estratégia do que as não vítimas (Grupo 2).

\section{Cruzamentos entre os Sexos e as Categorias Identificadas}

Foi utilizado o Teste de Qui-quadrado $\left(X^{2}\right)$ para verificar as diferenças entre os sexos e as categorias referentes às: percepções das crianças sobre quem são as pessoas que fazem parte da sua família; aos tipos de problemas com professores e colegas- enfrentados e relatados- e às estratégias de coping adotadas. A seguir, serão descritas apenas as análises que obtiveram resultados significativos.

A Tabela 13 mostra diferença significativa entre os sexos das crianças e o uso de agressões físicas como estratégia de coping para lidar com problemas com os colegas $\left(X^{2}=7,82 ; p<0,01\right)$. Os meninos adotam, com mais freqüência, este tipo de estratégia do que as meninas, quando estão diante de conflitos com seu(s) colega(s).

Tabela 11

Cruzamento entre os Grupos 1 (crianças vítimas de violência doméstica) e 2 (crianças não vítimas de violência doméstica) com Relação à Categoria "Agressões Verbais", Identificada a partir das Respostas à Questão: "Conte-me um problema com a sua professora" $(N=87 ; * 00,05)$

\begin{tabular}{ccccc}
\hline Grupo & Mencionou & Não mencionou & Total & $X^{2}$ \\
\hline 1 & $21(24,1 \%)$ & $28(32,1 \%)$ & $49(56,3 \%)$ & $10,92^{*}$ \\
2 & $4(4,5 \%)$ & $34(39 \%)$ & $38(43,6 \%)$ & \\
\hline Total & $25(28,7 \%)$ & $62(71,2 \%)$ & $87(100 \%)$ & \\
\hline
\end{tabular}

Tabela 12

Cruzamento entre os Grupos 1 (crianças vítimas de violência doméstica) e 2 (crianças não vítimas de violência doméstica) e a Categoria "Agressões Físicas", Identificada a partir das Respostas à Pergunta: "O que você far, quando tem um problema com seu(s) colega(s)?” ( $\left.N=87 ;{ }^{*} p<0,05\right)$

\begin{tabular}{ccccc}
\hline Grupo & Mencionou & Não mencionou & Total & $X^{2}$ \\
\hline 1 & $16(18,3 \%)$ & $33(37,9 \%)$ & $49(56,3 \%)$ & $7,68^{*}$ \\
2 & $3(3,4 \%)$ & $35(40,2 \%)$ & $38(43,6 \%)$ & \\
\hline Total & $19(21,8 \%)$ & $68(78,1 \%)$ & $87(100 \%)$ & \\
\hline
\end{tabular}

Tabela 13

Cruzamento entre os Sexos e a Categoria "Agressões Físicas", Identificada a partir dos Relatos sobre as Estratégias de Coping Adotadas quando bá Problema com o Colega $\left(N=87\right.$; $\left.{ }^{*} p<0,01\right)$

\begin{tabular}{ccccc}
\hline Sexo & Mencionou & Não mencionou & Total & $X^{2}$ \\
\hline Masculino & $15(17,2 \%)$ & $29(33,3 \%)$ & $44(50,5 \%)$ & $7,82^{* *}$ \\
Feminino & $4(4,5 \%)$ & $39(44,8 \%)$ & $43(49,4 \%)$ & \\
\hline Total & $19(21,8 \%)$ & $68(78,1 \%)$ & $87(100 \%)$ & \\
\hline
\end{tabular}


A Tabela 14 mostra que as meninas utilizam, com maior freqüência que os meninos, as agressões verbais como estratégia de coping, quando enfrentam problemas com seus colegas. Existe diferença significativa entre os $\operatorname{sexos}\left(X^{2}=7,79 ; p<0,01\right)$.

A Tabela 15 mostra que as meninas citam, com maior freqüência que os meninos, as agressões verbais dos colegas como um problema enfrentado com os mesmos. Existe diferença significativa entre os sexos nesta categoria $\left(X^{2}=5,72 ; p<0,05\right)$.

As meninas adotam, com mais freqüência que os meninos, a inação ("Não Fazer Nada"), quando enfrentam problemas com suas professoras.
A Tabela 17 mostra que existe diferença entre os sexos e a freqüência de respostas na categoria "Agressões Verbais" referente aos problemas enfrentados e relatados com a professora $\left(X^{2}=2,98 ; p<0,05\right)$. As meninas relataram mais este tipo de problema do que os meninos.

\section{Discussão}

Os resultados obtidos possibilitam a discussão de dados relevantes acerca das crianças vítimas e não vítimas de violência doméstica, e das diferenças entre meninos e meninas a partir dos relatos das crianças entrevistadas sobre os problemas enfrentados com professores e colegas e as

Tabela 14

Cruzamento entre os Sexos e a Categoria "Agressões Verbais", Identificada a partir dos Relatos Sobre as Estratégias de Coping Adotadas, quando bá Problema com o Colega $\left(N=87\right.$; $\left.{ }^{*} p<0,01\right)$

\begin{tabular}{ccccc}
\hline Sexo & Mencionou & Não mencionou & Total & $X^{2}$ \\
\hline Masculino & $0(0 \%)$ & $44(50,5 \%)$ & $44(50,5 \%)$ & $7,79 * *$ \\
Feminino & $7(8 \%)$ & $36(41,3 \%)$ & $43(49,4 \%)$ & \\
\hline Total & $7(8 \%)$ & $80(91,7 \%)$ & $87(100 \%)$ & \\
\hline
\end{tabular}

Tabela 15

Cruzamento entre os Sexos e a Categoria "Agressões Verbais", Identificada a partir dos Relatos das Crianças com Relação aos Problemas Enfrentados com os Colegas $\left(N=87 ;{ }^{*}<<0,05\right)$

\begin{tabular}{ccccc}
\hline Sexo & Mencionou & Não mencionou & Total & $X^{2}$ \\
\hline Masculino & $5(5,74 \%)$ & $39(44,8 \%)$ & $44(50,5 \%)$ & $5,72^{*}$ \\
Feminino & $14(16 \%)$ & $29(33,3 \%)$ & $43(49,4 \%)$ & \\
\hline Total & $19(21,8 \%)$ & $68(78,1 \%)$ & $87(100 \%)$ & \\
\hline
\end{tabular}

Tabela 16

Cruzamento entre os Sexos e a Categoria "Não Fazer Nada", Identificada a partir dos Relatos Sobre as Estratégias de Coping Adotadas para Lidar com um Problema Envolvendo a Professora $(N=87$; $\left.{ }^{*} p<0,05\right)$

\begin{tabular}{ccccc}
\hline Sexo & Mencionou & Não mencionou & Total & $X^{2}$ \\
\hline Masculino & $25(28,7 \%)$ & $19(21,8 \%)$ & $44(50,5 \%)$ & $2,98^{*}$ \\
Feminino & $32(36,7 \%)$ & $11(12,6 \%)$ & $43(49,4 \%)$ & \\
\hline Total & $57(65,5 \%)$ & $30(34,4 \%)$ & $87(100 \%)$ & \\
\hline
\end{tabular}

Tabela 17

Cruzamento entre os Sexos e a Categoria "Agressões Verbais", Identificada a partir das Respostas, com Relação aos Problemas Enfrentados com a Professora $\left(N=87{ }^{*} p<0,05\right)$

\begin{tabular}{ccccc}
\hline Sexo & Mencionou & Não mencionou & Total & $X^{2}$ \\
\hline Masculino & $9(10,3 \%)$ & $35(40,2 \%)$ & $44(50,5 \%)$ & $2,98^{*}$ \\
Feminino & $16(18,3 \%)$ & $27(31 \%)$ & $43(49,4 \%)$ & \\
\hline Total & $25(28,7 \%)$ & $62(71,2 \%)$ & $87(100 \%)$ & \\
\hline
\end{tabular}


estratégias de coping adotadas no ambiente escolar. As repreensões (orais e escritas) foram os problemas com professores mais citados pelas crianças do estudo. Este resultado pode ser explicado pelo fato de crianças e préadolescentes se incomodarem, quando são chamados a obedecer a regras ou quando alguém aponta os limites a serem respeitados (Steinberg, 1999). Entretanto, a segunda maior freqüência de respostas refere-se a agressões verbais por parte da professora. Com este resultado, é questionado o papel da professora no desenvolvimento dos seus alunos, bem como a qualidade das repreensões citadas anteriormente. As crianças deste estudo podem estar denunciando dificuldade das suas professoras em exercer a autoridade de forma adequada e afetiva, além de estarem manifestando incômodo em obedecer a regras e normas. Professores percebidos como agressivos, inadequados ou com dificuldades de estabelecer disciplina e bom rendimento dos seus alunos não representam fatores de proteção para as crianças (Henderson \& Milstein, 1996). O microssistema escolar pode representar para as crianças uma alternativa de apoio, que não encontram em seu microssistema familiar (Henderson \& Milstein, 1996). As reclamações das crianças desta pesquisa sobre as repreensões e as agressões verbais das professoras, incluindo gritos, xingamentos, deboches e ironias pode estar denunciando um sistema educacional que falha em exercer seu papel de rede de apoio social e protetiva para as crianças.

A estratégia de coping inação ("Fazer Nada"), adotada para lidar com um problema envolvendo a professora, obteve a maior freqüência de respostas. As crianças dispõem de menos recursos que os adultos para lidar com seus estressores, principalmente quando estes estão relacionados a seus pais, família, professores ou condições sócio-econômicas. Estes problemas fogem de seu controle pessoal. Por outro lado, as habilidades cognitivas das crianças se sofisticam durante a infância e adolescência, mas o mais alto nível de desenvolvimento cognitivo alcançado é de operações lógicas e formais (RyanWenger, 1992). Assim, muitas vezes, as crianças não agem por falta de competências e habilidades cognitivas para lidar com determinados estressores. Estas afirmações explicam o fato das crianças deste estudo relatarem com freqüência a inação ("Fazer Nada"). O coping- focalizado na emoção- e a inação estão associados, geralmente, aos baixos índices de controle sobre a situação e à percepção de seus recursos pessoais como insuficientes para lidar com o estresse a ser enfrentado (Almquist \& Hwang, 1999; Ryan-Wenger, 1992). Tais colocações são confirmadas nos relatos das crianças sobre as estratégias de coping que adotam frente aos problemas com as professoras, mas também apontam questões de hierarquia, envolvidas no processo proximal, entre as crianças do estudo e suas professoras. A professora é uma figura de autoridade, segundo relato das crianças, que não se baseia em uma relação de reciprocidade, afeto e equilíbrio de poder com seus alunos (Bronfenbrenner, 1979/1996). Provavelmente, os participantes se sintam apreensivos para agir quando têm um problema com a professora, temendo as conseqüências negativas de seus atos (castigos, suspensões, baixas notas, etc.) e evidenciando a falta de comunicação entre ambos. Esta pode ser a razão pela qual as crianças se percebem sem alternativas para adotar uma estratégia de coping eficaz e optam por não agir quando têm um problema com a professora. Tais conclusões são confirmadas pelas respostas das crianças às perguntas sobre sua auto-avaliação das estratégias de coping, adotadas frente a um problema com a professora. A maioria delas refere que, se passasse pelo mesmo problema que relataram uma outra vez, usariam a mesma estratégia que já haviam citado, justificando que a professora tem sempre a razão. Um estudo realizado por Dell'Aglio (2000) aponta resultados que corroboram estes achados. $\mathrm{Na}$ sua pesquisa, observou-se que as crianças utilizam estratégias de aceitação e inação, quando enfrentam problemas com adultos. Dell'Aglio salienta que estes comportamentos podem estar associados a questões de autoritarismo e hierarquia presentes nas relações entre adultos e crianças nas camadas de nível sócio-econômico baixo, das quais faziam parte as crianças entrevistadas no seu trabalho. Estas colocações confirmam os dados obtidos na pesquisa aqui descrita, bem como apóiam as explicações levantadas sobre os resultados.

Após identificar os problemas com a professora relatados pelas crianças e as estratégias de coping adotadas que obtiveram maior freqüência de respostas, convém comentar as semelhanças e diferenças entre os grupos de crianças, vítimas e não vítimas de violência doméstica. De uma maneira geral, com exceção de duas categorias, não ocorreu diferença significativa entre os dois grupos do estudo, no que se refere a estes aspectos. Este dado remete a um dilema sobre suas possíveis explicações. Esperava-se que as crianças não vítimas de violência doméstica relatassem estratégias de coping mais saudáveis e adaptativas do que as vítimas e que, também, por razões contextuais e pessoais, os dois grupos de crianças relatassem tipos de problemas qualitativamente diferentes. Muitos pesquisadores têm direcionado sua atenção para estudos que focalizam o potencial de coping enquanto preditor de adaptabilidade social (Antoniazzi, 2000; Endler \& Parker, 1990; Holahan, Moos \& Schaefer, 1996). As estratégias de coping que visam lidar com o evento estressante em si, ou seja, busca de informações sobre o problema e planificações de resolução para o mesmo são vistas como mais 
adaptativas e funcionais (Holahan, Moos \& Schaefer, 1996). Já as estratégias evitativas, como negação, distração ou inação tendem a dificultar o desenvolvimento saudável (Endler \& Parker, 1990). A semelhança entre as respostas das crianças vítimas e não vítimas de violência doméstica pode estar associada à ação de fatores de proteção presentes no contexto destas. As crianças vítimas de violência podem encontrar na escola tantos fatores de proteção (professores, SOE, colegas, etc.) que amenizem a influência do risco (violência) sobre seu desenvolvimento e façam com que elas apresentem estratégias de coping saudáveis. Por outro lado, os dados deste estudo sugerem que as professoras, provavelmente, não possam ser consideradas fatores de proteção responsáveis pelas estratégias adaptativas das crianças vítimas de violência doméstica, dado que justificaria a semelhança entre os grupos. O problema com as professoras, mais citado pelas crianças do estudo, foi as repreensões, seguidas das agressões verbais das professoras, e a estratégia mais usada nestes casos foi a inação, que segundo a literatura não é considerada uma estratégia saudável (Endler \& Parker, 1990). De acordo com estes resultados, pode-se levantar a hipótese de que as crianças não vítimas, mesmo não sofrendo violência doméstica, enfrentam outros tipos de risco no microssistema escolar e, com isso, têm seu desenvolvimento e interações sociais prejudicadas. Se a violência doméstica é tão danosa ao desenvolvimento, provavelmente o contexto ecológico escolar não oferece proteção a crianças não vítimas, pois elas também relatam estratégias de coping pouco adaptativas, quando lidam com problemas com seus professores. Estas crianças, mesmo não expostas à agressão em seu microssistema familiar, tomam conhecimento desta na escola e, através do modelo e exemplo dos colegas, também podem se tornar mais agressivas. Esta colocação explica a semelhança entre crianças vítimas e não vítimas de violência doméstica com relação aos problemas e estratégias de coping referentes a conflitos com os colegas. Convém enfatizar que tais afirmações são relevantes para intervenções em escolas. As crianças não vítimas de violência doméstica também devem ser focalizadas em programas preventivos realizados nestas instituições, tanto quanto as vítimas. Em alguns casos, em função da revelação do abuso, as professoras podem direcionar toda sua atenção às crianças vítimas de violência doméstica, desconsiderando os comportamentos de risco evidenciados pelas não vítimas.

Mesmo que os dois grupos de crianças entrevistadas se assemelhem na maioria de suas respostas, foi observada diferença significativa, quanto aos problemas com a professora enfrentados e relatados. As crianças vítimas de violência doméstica relatam com maior freqüência a categoria “Agressões Verbais". Este dado pode relacionarse às características do microssistema familiar das crianças que sofrem violência em casa e aos fatores de risco e proteção presentes nos ambientes nos quais interagem. Vivendo em situação de risco, as crianças vítimas de violência doméstica necessitam de educadores que lhes transmitam energia e força, para que estas possam desenvolver estratégias de coping adequadas para lidar com os problemas de seu processo de desenvolvimento e serem resilientes (Bronfenbrenner, 1979/1996, 1989, 1993, 1995; Bronfenbrenner \& Morris, 1998; Henderson \& Milstein, 1996). As crianças vítimas de violência doméstica, que participaram da pesquisa, trazem expectativas positivas sobre o comportamento de seus professores e se frustram. Elas vêm de microssistemas familiares nos quais sofrem violência de seus pais e parentes e/ou a testemunham com freqüência e esperam encontrar na escola um grupo de educadores que as apóie e com capacidade para auxiliá-los no seu desenvolvimento acadêmico e emocional. Por esta razão, pode-se inferir que as agressões verbais das professoras tenham maior impacto para estas e por isto sejam relatadas com maior freqüência.

Rutter (1999) salienta que os fatores de risco estão diretamente relacionados com as circunstâncias sociais e a maneira pela qual as pessoas se comportam. Elas constroem suas experiências através de ações e formam ciclos prejudiciais na promoção da resiliência. Ou seja, uma criança agressiva (que aprende este comportamento em casa), quando é agredida verbalmente pela sua professora, como exemplificado no relato das crianças deste estudo, tende a responder novamente com agressividade. A professora responde a esta agressivamente e, assim, sucessivamente. O ciclo está formado. A dimensão Contexto - microssistema familiar, no qual existe violência doméstica - e características da Pessoa - comportamento agressivo expõem as crianças ao risco e as tornam mais vulneráveis a desenvolver comportamentos desadaptados. Para quebrar este processo, é preciso que professores e outras pessoas, que têm contato com estas crianças, ofereçam a elas novos modelos e exemplos de interação. A agressividade não deve ser respondida com agressividade, mas com outro tipo de resposta mais adaptativa. É necessário que profissionais estejam cientes destes dados e sejam tolerantes com estas crianças, considerando o contexto no qual elas se desenvolvem.

A análise ecológica do macrossistema, em que se encontram estes professores e estas crianças, também deve ser levada em consideração. No Brasil, as formas de governo e as políticas econômicas e públicas desvalorizam a educação. Estes aspectos geram baixa remuneração para alguns professores de Ensino Fundamental, afetando sua 
motivação e resultando em um despreparo para lidar com os comportamentos dos alunos (Dias, Salzstein \& Millery, 1999). Este pode ser o caso dos professores do estudo. Por outro lado, para Freire (1998), as relações entre professores e jovens alunos no Brasil são mais afetivas que em outras culturas. Este fato é contrário aos dados obtidos e pode justificar o incômodo das crianças do estudo frente às repreensões e às agressões verbais de seus professores, pois existe uma expectativa cultural de proximidade afetiva destes ou das "tias" e "tios", como as crianças os costumam chamar, mas não está havendo reciprocidade.

Observa-se semelhança entre os sexos das crianças com relação aos problemas com colegas e professores enfrentados e relatados e às estratégias de coping adotadas. Esta semelhança pode estar associada ao fato de que as diferenças entre os sexos não parecem tão delimitadas na infância, mas tendem a ficar salientadas na adolescência e idade adulta. As diferenças observadas em crianças em idade escolar estão, geralmente, relacionadas à agressividade (Coie \& Dodge, 1997; Ruble \& Martin, 1997). Entretanto verificou-se diferença entre meninos e meninas com relação ao uso da estratégia de coping inação ("Não Fazer Nada") adotada para lidar com problemas com a professora. As meninas utilizam mais esta estratégia que os meninos. Este dado está associado a pressupostos teóricos que enfatizam que as meninas são mais passivas, delicadas, dependentes, ansiosas e medrosas que os meninos (Coie \& Dodge, 1998; Loeber \& Hay, 1997; Ruble \& Martin, 1998). Possivelmente, as meninas entrevistadas optem pela inação quando enfrentam um problema com a professora porque esta representa autoridade (questões de hierarquia) e não pode ser questionada ou atacada. Estas meninas também temem as conseqüências do uso de outras estratégias e, devido a suas características de passividade, escolhem não fazer nada. As meninas também relataram, com maior freqüência que os meninos, as agressões verbais por parte das professoras como um problema que enfrentam. Este dado pode estar associado ao fato de que se observam mais nas meninas que nos meninos características pessoais como sensibilidade e delicadeza e, por essas razões, elas podem se incomodar mais que os meninos com as agressões verbais das suas professoras (Coie \& Dodge, 1998; Loeber \& Hay, 1997; Ruble \& Martin, 1998).

Após referirem os tipos de problemas que enfrentam com professores e colegas, as crianças expuseram seus sentimentos na hora da percepção destes e depois do término e/ou resolução dos mesmos. Seja um problema com a professora ou com os colegas, no momento que o percebem, a maioria das crianças da amostra relata sentimentos negativos como "Me sinto mal", "Me sinto chateado", "Me sinto triste" com maior freqüência do que outros sentimentos. Os estudos sobre estratégias de coping apontam que, no momento da percepção do problema, o indivíduo experimenta sentimentos emocionais desagradáveis ou desconfortáveis e, a partir disto, adotará estratégias para resolver o conflito percebido e também amenizar este estado emocional negativo. A função da estratégia que emerge é alterar o problema existente no processo de interação PessoaContexto (Almquist \& Hwang, 1999; Lazarus \& Folkman, 1984; Ryan-Wenger, 1992). Com relação a estes sentimentos, não houve diferença significativa entre o relato de crianças vítimas e não vítimas e entre os sexos dos participantes, o que confirma a semelhança em relação a este processo de interação Pessoa-Contexto. Mesmo que umas vivam sob uma situação de risco específica (violência) e que ambos os grupos de crianças possuam características pessoais diferentes entre si, existem aspectos comuns a todas as crianças no que se refere ao processo de coping. Independente do risco e do sexo das crianças, elas, de uma maneira geral, quando percebem um problema, experimentam sentimentos desagradáveis (Boekaerts, 1996; Lazarus \& Folkman, 1984; Ryan-Wenger, 1992).

É importante comentar que um dos sentimentos mais citados pelas crianças da amostra total de crianças do estudo, no momento da percepção do problema com os colegas, foi a raiva. A raiva é uma das emoções básicas necessárias à sobrevivência. Quando bem direcionada, permite que o ser humano seja assertivo, lute pelos seus objetivos e se defenda, quando se sentir atacado. Entretanto, quando este sentimento foge do controle, dá origem ao ódio e manifesta-se sob formas agressivas (Maldonado, 1999). Mesmo que não exista diferença significativa entre crianças vítimas e não vítimas de violência doméstica, com relação aos sentimentos ao perceberem o problema, de uma maneira geral, a maioria das crianças da amostra refere agressividade, quando relatam problemas enfrentados (com professores e colegas) e estratégias que adotam para lidar com tais problemas com colegas.

Após a resolução do problema (com a professora ou com os colegas), os sentimentos de todas as crianças da amostra, de uma maneira geral, foram positivos, referindo bem-estar, alívio, felicidade. $\mathrm{Na}$ ausência de problemas, a criança se sente bem ou, após os sentimentos desagradáveis ocasionados pela percepção do problema, é natural que a criança relate se sentir bem, melhor e aliviada. Mesmo que a criança não tenha agido para resolver o problema (coping focalizado na emoção ou inação), depois que este por si só se resolve, as crianças relatam sentimentos positivos. Todos estes relatos de sentimentos estão relacionados ao Processo entre as características pessoais das crianças (dimensão 
Pessoa) e o Contexto no qual se deu o conflito. Neste caso, também não se evidenciou diferença significativa entre crianças que sofreram violência e as que não sofreram e entre os sexos dos participantes. As semelhanças revelam que estes sentimentos podem estar desvinculados de risco e não estão relacionados a diferenças entre os sexos, pois são típicos do desenvolvimento durante o ciclo vital e do processo de coping. O processo de coping envolve a interação da pessoa focalizada com seu ambiente, onde ela percebe um estressor e, geralmente, experimenta uma sensação física e emocional desagradável. Quando este problema é resolvido pela pessoa ou, por si só termina, a sensação incômoda também tende a desaparecer (Folkman \& Lazarus, 1980; Lazarus \& Folkman, 1984).

Quando abordados os problemas e as estratégias de coping da criança com relação aos seus colegas, observamse as maiores freqüências de respostas nas categorias: "Agressões Físicas" (chutar, bater, morder, empurrar, dar um soco, dar um tapa, etc.), referindo-se aos problemas e "Busca de Apoio de Alguém", como estratégia de coping. Essas foram as maiores freqüências de respostas, considerando a amostra total de crianças. $O$ fato das crianças apontarem as agressões físicas de seus colegas como um problema pode ser analisado dentro do ciclo vital. Na sua faixa etária, é natural que se incomodem com estes problemas de agressividade e manifestem comportamentos agressivos (Bronfenbrenner, 1979/ 1996, 1989, 1993, 1995; Bronfenbrenner \& Morris, 1998; Coie \& Dodge, 1998; Loeber \& Hay, 1997; Pierre \& Layzer, 1998). Por outro lado, os relatos das crianças também podem estar associados a características do macrossistema, refletindo uma situação sócio-histórico-cultural que revela aumento nos níveis de violência (Haase, Käppler \& Schaeffer, 2000). O macrossistema do conjunto das crianças do estudo reflete fatores econômicos (desemprego dos pais, pobreza, etc.) e culturais que influenciam o aumento dos casos de agressividade das crianças e da utilização desta agressão na educação dos filhos, nos relacionamentos pessoais e de trabalho, para conseguir status na sua comunidade, etc. (Bronfenbrenner, 1979/1996, 1989, 1993, 1995; Bronfenbrenner \& Morris, 1998; Haase \& cols., 2000). Especificamente, ainda, o fato de existirem crianças vítimas de violência na amostra total pode estar associado às altas freqüências de respostas em tais categorias. Estas crianças tendem a aprender este padrão violento em casa e repeti-lo na interação social, refletindo o Processo de interação entre a Pessoa e o Contexto no qual se desenvolve (Bandura, 1969, 1997; Bandura \& Walters, 1959; Bronfenbrenner, 1979/1996, 1989, 1993, 1995; Bronfenbrenner \& Morris, 1998). Entretanto, não se verificou diferença entre as crianças vítimas e não vítimas com relação aos problemas com os colegas. Neste caso, a discussão sobre as semelhanças entre os dois grupos de crianças deve ser retomada. As crianças não vítimas de violência doméstica, mesmo não sofrendo violência em casa, podem estar presenciando esta violência na escola com os colegas e também com professores, aprendendo o padrão agressivo, através da aprendizagem vicária e o repetindo nas suas interações com o grupo de iguais (Bandura 1969, 1997).

A estratégia de coping mais citada para lidar com problemas que envolvem colegas, incluindo os dois grupos de crianças, foi a busca de apoio de outras pessoas. As referências teóricas sobre os poucos recursos (físicos, cognitivos, financeiros, situacionais, etc.), que as crianças dispõem, para lidar sozinhas com seus estressores, explicam este resultado (Boekaerts, 1996; Ryan-Wenger, 1992; Summerfeldt \& Endler, 1996). Neste caso, elas relataram buscar ajuda junto aos pais, irmãos mais velhos, a própria professora, outros funcionários da escola e parentes próximos. $\mathrm{O}$ fato das crianças não mencionarem com grande freqüência a inação ("Não fazer nada"), como no caso do problema com a professora, pode ser explicado pela ausência de questões de hierarquia e autoridade envolvidas neste processo proximal. Com os colegas existe maior equilíbrio de poder nas relações, e as crianças, provavelmente, não se vislumbram sem alternativas de ação. Pelo contrário, elas buscam orientações, conselhos, ajuda de outras pessoas, em geral mais velhas que elas. No estudo de Dell'Aglio (2000), as crianças também referiram o uso de ações mais diretas como busca de apoio social ou estratégias agressivas para lidar com conflitos com pares o que corrobora os resultados deste estudo e a discussão sobre a relação entre estratégias de coping infantis e questões de hierarquia presentes no contexto das crianças.

Este dado é relevante para o desenvolvimento de programas de intervenção e de prevenção. As crianças precisam de uma rede social afetiva eficaz e disponível para auxiliá-las nas suas estratégias de coping frente aos problemas na escola (Zaleski, Levey-Thors \& Schiaffino, 1998). E, segundo seu relato, buscam apoio, pedem ajuda e devem ser devidamente compreendidas quando o fazem. Pais e professores devem estar atentos e agir em parceria, entendendo que ninguém se desenvolve sozinho, as pessoas devem ajudar umas as outras, sabendo solicitar auxílio adequadamente, quando necessitam. A primeira vez que uma criança é ajudada, ela aprende a ajudar (Eisenberg \& Strayer, 1987; Lisboa, Alves \& Dotta, 2000). Adultos violentos e com dificuldades de empatia podem ter sido crianças que não foram auxiliadas no momento que necessitaram.

Mesmo que as crianças vítimas e não vítimas de violência doméstica se assemelhem, na maioria das vezes, no que diz respeito às estratégias de coping adotadas para lidar com 
problemas com seus colegas verificou-se diferença significativa na categoria "Agressões Físicas". As crianças vítimas de violência utilizam, com maior freqüência, agressões físicas do que as não vítimas como estratégia de coping para lidar com seus colegas. Segundo a literatura, estas crianças podem aprender um padrão violento de interação em família, através do qual mediam suas ações e comportamentos na esfera social. A violência sofrida no microssistema familiar é levada para os demais ambientes que a criança freqüenta, e estas crianças utilizam estratégias adaptativas agressivas, as quais são ineficazes e provocam rejeição e conflitos nos ambientes em que interagem (Bandura \& Walters, 1959; Caminha, 1999; Coie \& Dodge, 1998; Ladd \& Burgess, 1999; Loeber \& Hay, 1997; McWhiter, 1999; Pires, 1999). Estas afirmações se referem ao Processo das crianças, no qual interagem suas características comportamentais (dimensão Pessoa) e a influência do microssistema familiar.

As meninas relatam as agressões verbais por parte dos colegas como um problema que enfrentam com maior freqüência que os meninos. De acordo com os pressupostos teóricos citados anteriormente, meninas tendem a ser mais delicadas e sensíveis e, por isso, podem se incomodar mais facilmente que os meninos com xingamentos, deboches ou ironias (Coie \& Dodge, 1998; Ruble \& Martin, 1998). Os resultados do estudo mostram também que as meninas usam mais agressões verbais como estratégia de coping para lidar com um problema com seus colegas, enquanto que os meninos usam mais agressões físicas.

A auto-avaliação das crianças acerca de suas estratégias de coping com relação aos colegas diferiu da avaliação que relataram, quando o problema e as estratégias diziam respeito a problemas com a professora. Quando perguntadas sobre o que fariam caso ocorresse o mesmo problema com sua professora, a maioria das crianças informou que usaria a mesma estratégia já relatada, alegando que a professora tem sempre a razão e com esta não se pode discutir (questões de hierarquia com autoridade). Com relação à auto-avaliação das estratégias utilizadas junto aos colegas, as respostas das crianças se dividiram em: usar estratégias diferentes das usadas anteriormente porque refletiram e pensaram em outras alternativas de ação; e usar a mesma estratégia porque esta é eficaz. As crianças que relataram que usariam outra estratégia de coping diferente da anterior, porque raciocinaram no momento que foram questionadas pelo pesquisador. Isso exemplifica o que as teorias sobre julgamento moral (base cognitiva) chamam de pensamento explícito e raciocínio proposicional. As crianças, geralmente, têm dificuldades em justificar o porquê de suas respostas, mas quando o fazem suas falas traduzem racionalizações ex-post-facto (Haidt \&
Koller, 1994; Haidt, Koller \& Dias, 1993). Ou seja, são pensamentos, raciocínios ou argumentações que vieram à tona, naquele momento, em resposta a uma pergunta ou a qualquer outro estímulo. As crianças param, pensam, hesitam e depois de um tempo sugerem novas estratégias de coping que poderiam utilizar. Tal fato pode ser positivo, possibilitando que as crianças reflitam e flexibilizem suas estratégias, adaptando-as de acordo com os contextos e situações. A avaliação da eficácia ou não da estratégia utilizada é muito importante para que a criança aprimore suas estratégias de coping, permitindo com que esta seja resiliente frente aos estresses que enfrenta.

A eficácia percebida pelas crianças acerca das suas estratégias de coping deve ser comentada. A avaliação de uma estratégia como eficaz é um julgamento subjetivo e não significa dizer que esta estratégia é adaptada. Uma criança que usa agressão como estratégia de coping pode estar conseguindo atingir seus objetivos, a estratégia é eficaz no ponto de vista da criança, mas não saudável, pois pode implicar conseqüências negativas no seu desenvolvimento (Hoolahan \& Moos, 1987; Ladd \& Burgess, 1999; Ladd \& Profilet, 1996; McCare \& Costa, 1986; Zeidner \& Saklofske, 1996). Crianças vítimas de violência aprendem, no seu microssistema familiar, o uso da agressão como estratégia de coping - legítima para atingir seus objetivos. Elas convivem diariamente com o exemplo dos pais e não conseguem vislumbrar outras formas de enfrentar estresses do ambiente. Estas estratégias podem ser eficazes, para resolver seus problemas por certo tempo, mas, ao longo do desenvolvimento, podem trazer sérias conseqüências, desde rejeição no grupo da escola até comportamento delinqüente e criminal na adolescência.

Os objetivos deste estudo foram comparar crianças vítimas e não vítimas de violência doméstica, meninos e meninas no que se refere aos problemas com professores e colegas enfrentados no ambiente escolar e às estratégias de coping utilizadas. Em primeiro lugar, verificaram-se semelhanças entre os grupos com relação aos problemas com professores e colegas enfrentados no ambiente escolar e as estratégias de coping utilizadas. Isso remete a um dilema sobre os fatores protetivos envolvidos no microssistema escolar, no qual, ou as crianças vítimas de violência encontram fatores de proteção e são resilientes, ou as não vítimas encontram fatores de risco que prejudicam seu desenvolvimento. Além disso, pode-se inferir que isto ocorre porque todas as crianças se desenvolvem de forma semelhante, de acordo com as etapas do ciclo vital e, mesmo sob condições adversas, possuem potencial para se desenvolver saudavelmente. Os trabalhos realizados em escolas devem focalizar não só as crianças vítimas de violência doméstica, mas também as não vítimas. É pouco provável 
que, sem dificuldades, as crianças mudem sua forma de interagir de uma hora para a outra. É necessário oferecer a estas oportunidades de reflexão e exemplos de novas alternativas para lidar com problemas, considerando que elas trazem consigo influências contextuais e culturais fortes que devem ser modificadas. Pode ser mais fácil intervir no contexto e nas relações de hierarquia do que propor e desenvolver junto com as crianças estratégias de coping mais eficazes. O movimento gerado pela intervenção no contexto ecológico (Ex.: escola) e nas relações de hierarquia existentes pode resultar na utilização de novas estratégias mais adaptativas e eficazes por parte das crianças.

A questão da violência doméstica é um problema de saúde pública que cresce atualmente. Embora já estejam sendo realizados, estudos e pesquisas, junto a esta população, são essenciais, enfatizando a necessidade de intervenção adequada e específica. A crença no potencial saudável destas crianças é fundamental para a garantia de um desenvolvimento mais adaptativo, mesmo na presença do risco. Escolas e professores podem ser importantes fatores de proteção que, no entanto, mostram-se muito despreparados. Evidencia-se a necessidade de capacitação destes profissionais com relação a aspectos do desenvolvimento infantil e a violência doméstica, assim como o conhecimento sobre serviços de proteção e encaminhamento presentes na comunidade.

O estudo junto a populações de risco deve enfatizar o lado positivo e não somente as patologias. Por que não auxiliar as crianças agressivas a canalizarem sua raiva para outras atividades produtivas na própria escola? Por que não oferecer a famílias e crianças que vivenciam violência exemplos de outros tipos de estratégias de coping, salientando sua eficácia e conseqüências positivas? O problema da violência doméstica, atualmente, é também um problema cultural, presente no macrossistema. Estudos, pesquisas e palestras que discutam este assunto podem agir no sentido de desmistificar crenças sobre práticas educativas que prejudicam as crianças no seu desenvolvimento. E ainda fortalecer redes de apoio sociais existentes e comprometer a sociedade como um todo na luta contra este problema. Por esta razão, entraves burocráticos para pesquisas, nesta área, devem ser eliminados. Discussões sobre códigos de ética existentes devem considerar as especificidades da pesquisa com crianças vítimas de violência doméstica, no momento de exigir documentos e autorizações para projetos de pesquisa.

\section{Referências}

Almqvist, K. \& Hwang, P. (1999). Iranian refugees in Sweden: Coping processes in children and their families. Childhood, 6, 167-188.
Amirkhan, J. H. (1990). A factor analytically derived measure of coping: The coping strategy indicator. Journal of Personality and Social Psychology, 59, 1066-1074.

Antoniazzi, A. S. (2000). Desenvolvimento de instrumentos para avaliação de coping em adolescentes brasileiros. Tese de doutorado não publicada. Curso de Pós-Graduação em Psicologia do Desenvolvimento, Universidade Federal do Rio Grande do Sul. Porto Alegre, RS.

Bandura, A. \& Walters, R. H. (1959). Adolescent aggression: A study of the influence of child-training practices and family interrelationships. New York: The Ronald Press Company.

Bandura, A. (1969). Modificação do comportamento. Rio de Janeiro: Interamericana.

Bandura, A. (1997). Self-efficacy: The exercise of control. New York: W. H. Freeman Company.

Boekaerts, M. (1996). Coping with stress in childhood and adolescence. Em M. Zeidner \& N. S. Endler (Orgs.), Handbook of coping: Theory, research, applications (pp. 452-484). New York: John Wiley.

Bronfenbrenner, U. (1989). Ecological systems theory. Annals of Child Development, 6, 187-249.

Bronfenbrenner, U. (1993). The ecology of cognitive development: Research models and fugitive findings. Em R. Wozniak \& K. Fischer (Orgs.), Development in context: Acting and thinking in specific environments (pp. 3-44). Hillsdale, NJ: Erlbaum.

Bronfenbrenner, U. (1995). The bioecological model from a life course perspective: Reflections of a participant observer. Em P. Moen, G. H. Elder \& K. Lüscher (Orgs.), Examining lives in context (Vol. 1, pp. 599618). Washington: American Psychological Association.

Bronfenbrenner, U. (1996). A ecologia do desenvolvimento bumano: Experimentos naturais e planejados (M. A. Veríssimo, Trad.). Porto Alegre: Artes Médicas. (Original publicado em 1979)

Bronfenbrenner, U. \& Morris, P. (1998). The ecology of developmental processes. Em Damon (Org. Série) \& R. M. Lerner (Org. Volume), Handbook of child psychology: Theoretical models of buman development (Vol. 1, pp. 993-1027). New York: John Wiley.

Caminha, R. (1999). A violência e seus danos à criança e adolescente. Em AMENCAR (Org.), Violência doméstica (pp.43-60). Brasília, UNICEF.

Carver, C. S. \& Scheier, M. F. (1994) Situational coping and coping dispositions in stressful transaction. Journal of Personality and Social Psychology, 56, 267-283.

Coie, J. \& Dodge, K. (1998). Aggression and antisocial behavior. Em W. Damon (Org. Série) \& N. Eisenberg (Editora do Volume), Handbook of cbild psycbology: Social, emotional, and personality development (Vol. 3, pp. 779-862). New York: John Wiley.

Conselho Federal de Psicologia (2000). Resolução para pesquisa com seres bumanos. Resolução 016/2000, Brasília.

Cowan, P. A, Cowan, C. P. \& Schulz, M. (1996). Thinking about resilience in families. Em E. M. Hetherington \& E. A. Blechmann (Orgs.), Stress, coping, and resilience in children and families (pp.1-38). New Jersey: Lawrence Erlbaum.

Cummings, E. M., Hollenbeck, B., Ianotti, R., Radke-Yarrow, M. \& ZahnWaxler, C. (1986). Early organization of altruism and aggression: Developmental patterns and individual differences. Em C. ZahnWaxler, E. M. Cummings \& R. Iannotti (Orgs.), Altruism and aggression: Biological and social origins (pp. 165-188). New York: Cambridge University Press.

Dell' Aglio, D. D. (2000). O processo de coping, institucionalização e eventos de vida em crianças e adolescentes. Tese de Doutorado não-publicada. Curso de Pós-Graduação em Psicologia do Desenvolvimento, Universidade Federal do Rio Grande do Sul. Porto Alegre, RS.

Dias, M. G. B. B., Salztein, H. D. \& Millery, M. (1999). Raciocínio moral em interação social: Um estudo sobre sugestionabilidade. Estudos de Psicologia, 4, 199-220.

Eccles, J. S. \& Roeser, R. W. (1999). School and community influences on human development. Em M. H. Bornstein \& M. E. Lamb (Orgs.), Developmental psychology: An advanced textbook (4a ed., pp. 451-502). Mahwah, NJ: Lawrence Erlbaum.

Eisenberg, N. \& Strayer, J. (1987). Empatby and its development. New York: Cambridge University Press. 
Endler, N. S. \& Parker, J. D. A. (1990). Multidimensional assessment of coping: A critical evaluation. Journal of Personality and Social Psychology, $58,844-854$

Folkman, S. \& Lazarus, R. S. (1980). An analysis of coping in a middle-aged community sample. Journal of Health and Social Behavior, 21, 219-239.

Haase, V. G., Käppler, C. \& Schaeffer, A. (2000). Um modelo de intervenção psicoeducacional para prevenção da violência no ambiente familiar e escolar. Em V. G. Haase, R. Rothe-Neves, C. Käppler, M. L. M. Teodoro \& G. M. O. Wood (Orgs.), Psicologia do Desenvolvimento: Contribuições disciplinares. Belo Horizonte: Departamento de Psicologia, FAFICH-UFMG.

Haidt, J., Koller, S. H. \& Dias, M. (1993) Affect, culture and morality, or is it wrong to eat your dog? Journal of Personality and Social Psychology, 65, 613-628.

Haidt, J. \& Koller, S. H. (1994). Julgamento Moral nos Estados Unidos e no Brasil: Uma visão intuicionista. Psicologia: Reflexão e Crítica, 7, 75-92.

Heller, S. S., Larrieu, J. A., D’Imperio, R. \& Boris, N. W. (1999). Research on resilience to child maltreatment: Empirical considerations. Cbild Abuse and Neglect, 23, 321-338.

Henderson, N. \& Milstein, M. M. (1996). Resiliency in schools: Making it happens for students and educators. California: Corwin.

Holahan, C. J. \& Moos, R. H. (1985). Life stress and health: Personality, coping and family support in stress resistance. Journal of Personality and Social Psychology, 49, 739-747.

Holahan, C. J., Moos, R. H. \& Schaefer, J. A. (1996). Coping, stress, resistance, and growth: Conceptualizing adaptive functioning. Em M. Zeidner \& N. S. Endler (Orgs.), Handbook of coping: Theory, research, applications (pp. 24-43). New York: John Wiley.

Jessor, R. (1993). Successful adolescent development among youth in high-risk settings. American Psychologist, 48, 117-126.

Ladd, G. \& Burgess, K. (1999). Charting the relationship trajectories of aggressive, withdrawn and aggressive/withdrawn children during early grade school. Child Development, 70, 910-929.

Ladd, G. W. \& Profilet, S. M. (1996). The child behavior scale: A teacher report measure of young children's aggressive, withdrawn, and prosocial behavior. Developmental Psychology, 32, 1008-1023.

Lazarus, R. S. \& Folkman, S. (1984). Stress, appraisal and coping. New York: Springer.

Lisboa, C. S. M, Alves, P. B. \& Dotta, R. M (2000). Infância: Sexualidade, agressividade e AIDS. Material didático não-publicado. Curso de PósGraduação em Psicologia do Desenvolvimento, Universidade Federal do Rio Grande do Sul, Porto Alegre, RS.

Lisboa, C. S. M. (2001). Estratégias de coping e agressividade: Um estudo comparativo entre vítimas e não vítimas de violência doméstica. Dissertação de Mestrado não-publicada. Curso de Pós-Graduação em Psicologia do Desenvolvimento, Universidade Federal do Rio Grande do Sul. Porto Alegre, RS.

Loeber, F. \& Hay, D. (1997). Key issues in the developmental of aggression and violence from childhood to early adulthood. Annual Review of Psychologal Development, 48, 371-410.
Lopez, D. F. \& Little, T. D. (1996). Children's action-control beliefs and emotional regulation in the social domain. Developmental Psychology, 32, 299-312.

Maldonado, M. T. (1999). Construindo a paz. Em J. Gomes-Pedro (Org.), Stress e violência na criança e no jovem. (pp. 279-292). Lisboa: Seção Editorial da Associação de Estudantes da Faculdade de Medicina de Lisboa.

McCrae, R. R. \& Costa, P. T. Jr. (1986). Personality, coping and coping effectiveness in an adult sample. Journal of Personality, 54, 385- 405.

McWhirter, P. (1999). La violencia privada. American Psychologist, 54, 37-49.

Ministério da Saúde (1996). Informe Epidemiológico do SUS. Resolução 196/ 96, Suplemento 3, Ano V, n. 2. Brasília: Fundação Nacional de Saúde.

Pierre, R. G. \& Layzer, J. I (1998). Improving the life chances of children in poverty: Assumptions and what we have learned. Social Policy Report: Society for Research in Child Development, 4, 1-25.

Pires, J. (1999). Violência na infância: Aspectos clínicos. Em AMENCAR (Org.), Violência doméstica (pp.61-70). Brasília: UNICEF.

Rubin, K. H., Coplan, R. J., Nelson, L. J., Cheah, C. S. L. \& Lagace-Seguin, D. (1999). Peer relationships in childhood. Em M. H. Bornstein \& M. E. Lamb (Orgs.), Developmental psychology: An advanced textbook (4a ed., pp. 451-502). Mahwah, NJ: Lawrence Erlbaum.

Ruble, D. N. \& Martin, C. L. (1998). Gender development. Em W. Damon (Org. Série) \& N. Eisenberg (Editora do Volume), Handbook of cbild psychology: Social, emotional, and personality development (Vol. 3, pp. 9331016). New York: John Wiley \& Sons.

Rutter, M. (1999). Resilience concepts and findings: Implications for family therapy. Journal of Family Therapy, 21, 119-144.

Ryan-Wenger, N. (1992). A taxonomy of children's coping strategies: A step toward theory development. American Journal of Orthopsychiatry, 62, 256-263.

Seiffge-Krenke, I. \& Shulman, S. (1990). Coping style in adolescence: A cross cultural study. Journal of Cross-Cultural Psychology, 21, 351-377.

Steinberg, L. (1999). Adolescence. New York: Mac Graw-Hill.

Stone, A. A., Greenberg, M. A., Kennedy-Moore, E. \& Newman, M. G. (1991). Self-report, situation-specific coping questionnaires: What are they measuring? Journal of Personality and Social Psychology, 61, 711735.

Summerfeldt, L. \& Endler, N. (1996). Coping with emotion and psychopathology. Em M. Zeidner \& N. Endler (Orgs.), Handbook of coping: Theory, research, applications (pp. 602-639). New York: John Wiley.

Zaleski, E. H. Levey-Thors C. \& Schiaffino, K. M. (1998). Coping mechanisms, stress, social support, and health problems in college students. Applied Developmental Science, 2, 127-137.

Zeidner, M. \& Saklofske, D. (1996). Adaptative and maladaptative coping. Em M. Zeidner \& N. S. Endler (Orgs.), Handbook of coping: Theory, research, applications (pp. 503-531). New York: John Wiley.

Zimmermann, M. A. \& Arunkumar, R. (1994). Resilience research: Implications for schools and policy. Social Policy Report: Society for Research in Child Development, 8, 1-18.

Recebido: 27/08/2001

Revisado: 19/02/2001

Aceito: $01 / 03 / 2002$

Sobre as autoras

Carolina Lisboa é Mestre em Psicologia do Desenvolvimento e Doutoranda do Curso de Pós-graduação em Psicologia do Desenvolvimento da Universidade Federal do Rio Grande do Sul (UFRGS). Membro do CEP-RUA/UFRGS, coordenadora do NEDECC- Núcleo de Estudos sobre Desenvolvimento Comunitário e Cidadania, do PISAD- Programa de intervenção em Sexualidade Agressividade AIDS e Drogas, professora do Curso de Psicologia da FEEVALE/Novo Hamburgo-RS e do Curso de Especialização em Psicologia Clínica, na terminalidade de Saúde Comunitária/UFRGS.

Sílvia Helena Koller é Professora do Departamento de Psicologia do Desenvolvimento e da Personalidade da Universidade Federal do Rio Grande do Sul (UFRGS), Mestre em Psicologia do Desenvolvimento pela UFRGS, Doutora em Educação pela PUCRS. Coordenadora do Centro de Estudos Psicológicos sobre Meninos e Meninas de Rua (CEP-RUA), Instituto de Psicologia (UFRGS). Pesquisadora do CNPq.

Fernanda Freitas Ribas, Kelly Bitencourt, Lízia Pacheco Porciúncula e Renata Busnello De Marchi são Graduandas do Curso de Psicologia da Universidade Federal do Rio Grande do Sul (UFRGS) e Membros do CEP-RUA/UFRGS.

Letícia Oliveira é graduanda do Curso de Psicologia da Pontifícia Universidade Católica do Rio Grande do Sul e Membro do CEP-RUA/UFRGS. 


\section{Anexo A}

Entrevista Estruturada para Avaliar Estratégias de Coping e Problemas Enfrentados por Crianças no Microssistema Escolar

1. Qual é o seu nome?

2. Você sabe o dia que nasceu? Ou Você sabe o dia do seu aniversário?

3. Qual é o nome da sua mãe?

4. Você sabe a idade dela?

5. Sua mãe trabalha? O que ela faz?

6. Qual é o nome do seu pai?

7. Você sabe a idade dele?

8. Seu pai trabalha? O que ele faz?

9. Conte-me quem é a sua família?

10. Com quem você mora?

Agora vamos conversar um pouco sobre a sua escola...

1. Faz tempo que você estuda nessa escola? Você gosta daqui?

2. Como você vem para escola?

3. Conte-me um problema que você tenha tido com a sua professora?

4. O que você sentiu neste momento?

5. O que você fez?

6. Como você se sentiu depois que o problema se resolveu ou terminou?

7. Se este problema, o mesmo problema, acontecesse de novo o que você faria? Por quê?

8. Conte-me um problema que você tenha tido com algum colega seu?

9. O que você sentiu neste momento?

10. O que você fez?

11. Como você se sentiu depois que o problema se resolveu ou terminou?

12. Se este problema, o mesmo problema, acontecesse de novo o que você faria? Por quê? 